\title{
VISUALISASI KEMASAN KERIPIK PISANG ANEKA SEBAGAI KULINER KHAS LAMPUNG
}

\section{[Aneka Banana Chips Packaging Visualization as Lampung Typical Culinary]}

\author{
Syarip Hidayat ${ }^{1^{*}}$, Khairunisa Baby Setiawan ${ }^{2 *}$ \\ ${ }^{1,2}$ Telkom University, Fakultas Industri Kreatif, Desain Komunikasi Visual \\ Diterima: 1 Agusts 2018/ Disetujui: 12 Oktober 2018
}

\begin{abstract}
Lampung is a province that located on the easternmost of Sumatera island. Lampung is also traversed by a cross-lane of Sumatera that has a direct effect on the economic sector because it allows peoples to visit Lampung easily. It makes Lampung oftenly visited by tourists. The interesting thing about Lampung is its beach tourism which can attract domestic and foreign tourists. Tourists also do culinary tours and bring them home as a souvenirs and banana chips is the most popular one. Lampung typical culinary has a power to attract tourism. Lampung has three main commodities such as plantation, agriculture, and fishery. Banana chips are the result of one of Lampung's prime commodities, that is plantation. Bananas are cultivated with smallholder plantation systems and can be used as one of the business core. Unfortunately, the visualization of Lampung's uniqueness was not attached on its packaging by Aneka, as the producer of banana chips. So, the visualization of Lampung's uniqueness on Aneka Banana Chips packaging are needed. It can makes people know that Aneka Banana Chips is a part of Lampung typical culinary. The method used in this research is qualitative research method by collecting data such as direct observation, interview, and literature study. What's being expected from this packaging design is to make banana chips looks and known as Lampung culinary. Visualization of this packaging is useful for the uniqueness of Lampung can be visualized in the packaging. So that people can better know that the product comes from Lampung.
\end{abstract}

Keywords: Lampung, Culinary, Banana Chips, Packaging

\begin{abstract}
ABSTRAK
Lampung merupakan provinsi yang terletak di ujung timur pulau Sumatera. Lampung juga dilalui oleh jalur lintas Sumatera yang memiliki efek langsung terhadap perekonomian masyarakat dan memudahkan pendatang untuk berkunjung ke Lampung. Hal ini membuat Lampung kerap dikunjungi oleh wisatawan dari luar wilayah Lampung sendiri. Hal yang menarik dari Lampung yaitu wisata pantainya yang diminati oleh wisatawan domestik dan asing. Wisatawan juga melakukan wisata kuliner yang dijadikan sebagai oleh-oleh untuk mereka bawa pulang. Kuliner khas Lampung yang paling diminati adalah keripik pisang. Kuliner khas Lampung memiliki potensi untuk menjadi daya tarik wisata. Lampung memiliki tiga komoditas unggulan seperti perkebunan, pertanian, dan perikanan. Keripik pisang merupakan hasil dari salah satu komoditas unggulan Lampung yaitu perkebunan. Pisang dibudidayakan dengan sistem perkebunan rakyat dan dapat dijadikan salah satu bisnis utama. Namun sayangnya, produsen keripik pisang Lampung yaitu Aneka belum menyertakan visualisasi kekhasan Lampung pada kemasan produk mereka. Maka dari itu, visualisasi kekhasan Lampung pada kemasan memang dibutuhkan agar keripik pisang Aneka semakin dikenal oleh masyarakat sebagai bagian dari kuliner khas Lampung. Metode yang digunakan adalah metode penelitian kualitatif dengan pengumpulan data seperti observasi langsung, wawancara, dan studi pustaka. Visualisasi kemasan ini bermanfaat agar kekhasan Lampung dapat tervisualisasikan dalam kemasan. Sehingga masyarakat bisa lebih mengetahui bahwa produk tersebut berasal dari Lampung.
\end{abstract}

Kata kunci: Lampung, Kuliner, Keripik Pisang, Kemasan

*email: syarip@telkomuniversity.ac.id 


\section{PENDAHULUAN}

Lampung merupakan provinsi yang terletak di ujung Timur Pulau Sumatera. Lampung juga dilalui oleh jalur lintas Sumatera yang membantu memudahkan pendatang untuk berkunjung ke Lampung. Selain itu, terdapat banyak destinasi wisata pantai yang menarik di Lampung dan terkenal hingga ke mancanegara. Hal ini membuat Lampung kerap dikunjungi oleh wisatawan dari luar wilayah Lampung. Apalagi setelah rampungnya Tol Trans Sumatera yang dapat mempersingkat perjalanan dari Pelabuhan Bakauheni menuju Kota Bandar Lampung. Jika melalui jalan lintas non-tol dapat menghabiskan waktu sekitar dua hingga tiga jam, pengguna jalan dapat mempersingkat penggunaan waktu menjadi satu setengah jam menuju Kota Bandar Lampung.

Semakin mudahnya akses menuju Kota Bandar Lampung memiliki efek langsung terhadap kota ini. Terutama dalam hal perekonomian. Dikutip dari Republika.co.id dengan judul berita "Sri Mulyani Sebut Tol Trans Sumatera Dongkrak Perekonomian”, ujar Sri Mulyani di Jakarta, 27 Desember 2017. Ia juga menyebutkan total manfaat dari keseluruhan dampak permanen dari Tol Trans Sumatera dapat menembus Rp 769,5 triliun. Di mana, angka tersebut jauh lebih besar dari nilai proyek itu sendiri. Jika dilihat manfaatnya lebih luas lagi, masyarakat dapat menghemat biaya operasional pembiayaan. Begitu juga dalam hal ongkos transportasi menuju Lampung. Sehingga, arus wisatawan dari luar kota menuju Lampung pun terus meningkat dengan adanya kemudahan ini.

Fakta tersebut memberikan kesempatan untuk mengembangkan wisata dan kuliner khas Lampung. Lampung memiliki destinasi wisata pantai yang cukup diminati banyak masyarakat Indonesia. Terdapat beberapa destinasi wisata pantai favorit. Selain wisata pantai, biasanya wisatawan juga melakukan wisata kuliner yang juga dijadikan oleh-oleh untuk mereka bawa pulang. Ada beberapa makanan khas
Lampung yang harus dicoba untuk dinikmati saat berwisata ke Lampung maupun untuk dijadikan oleh-oleh. Kuliner khas Lampung dihasilkan dari hasil alam Lampung sendiri. Baik dari sektor pertanian, perkebunan, maupun perikanannya sebagai bidang unggulan yang difokuskan oleh Pemerintah

Provinsi Lampung. Dikutip dari finance.detik.com dengan judul berita "Jokowi Ingin Tingginya Ekonomi Lampung berefek ke Orang Miskin". Jokowi menjelaskan bahwa Ia melihat kini perekonomian di berbagai daerah termasuk di Pulau Jawa mulai meningkat dan tumbuh semakin cepat seperti misalnya Lampung yang bisa tumbuh sebesar $5,15 \%$. Presiden Jokowi juga meminta agar perekonomian Lampung yang meningkat ini harus bisa berdampak langsung terhadap 13,8\% penduduk miskin yang masih ada di Lampung. Ia meyakini bahwa kedepannya perekonomian Lampung bisa tumbuh lebih cepat lagi dengan syarat betul-betul fokus pada penggarapan sektor ungulan dan mengembangkan apa yang menjadi bisnis utama Provinsi Lampung. Menurut Jokowi pada 6 Maret 2017 di Jakarta.

Keripik pisang dapat dijadikan sebagai kuliner andalan yang dapat dijadikan oleh-oleh khas Lampung karena memiliki potensi untuk menjadi daya tarik wisata selain wisata pantai. Keripik pisang Lampung terbuat dari pisang kepok yang dibudidayakan dengan sistem perkebunan rakyat serta diolah secara tradisional untuk mempertahankan keaslian pisangnya.

Keripik pisang Lampung banyak diminati oleh wisatawan, salah satunya yang diproduksi oleh Aneka karena harga yang murah dan varian rasa yang banyak seperti coklat, susu, keju, asin, manis, stroberi, melon, greentea, barbeque, hingga balado. Namun sayangnya, potensi tersebut tidak dibarengi dengan adanya visualisasi kekhasan Lampung yang melekat pada kemasan keripik pisang Aneka ini. 


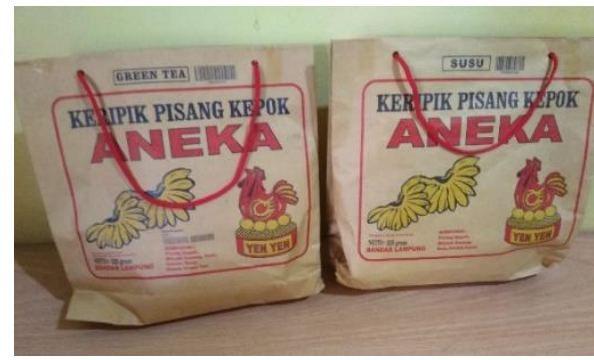

Gambar 1 Kemasan Keripik Pisang Aneka

(Sumber: K. Setiawan, 2018)

Maka dari itu, dibutuhkan kemasan yang mencerminkan bahwa keripik pisang merupakan makanan khas Lampung. Dengan adanya identitas visual Lampung pada kemasan keripik pisang ini, diharapkan akan semakin banyak masyarakat yang mengetahui bahwa keripik pisang merupakan kuliner khas Lampung.

\section{Identifikasi Masalah}

Pada kemasan keripik pisang Aneka, tidak ada unsur visual yang menunjukkan bahwa produk tersebut berasal dari Lampung.

\section{Tujuan dan Manfaat Penelitian}

Agar khalayak sasaran dapat mengetahui bahwa keripik pisang Aneka merupakan produk yang berasal dari Lampung.

\section{KAJIAN TEORI}

\section{Teori Kemasan}

Menurut Sri Julianti dalam bukunya The Art of Packaging Design (2014:15-16), kemasan merupakan sebuah tempat untuk meningkatkan nilai serta fungsi sebuah produk. Apabila dirinci lebih jauh, sebuah fungsi kemasan dapat dirangkum sebagai berikut:

1. Melindungi dan menjaga kualitas produk

2. Membuat produk lebih tahan lama

3. Sebagai sarana komunikasi produk dan branding kepada konsumen

4. Membantu distribusi produk dari produsen sampai ke tangan konsumen
5. Membuat produk dapat diproduksi secara massal

6. Menambah minat beli dengan merangsang panca indera dari khalayak sasarannya yaitu dengan melihat, mendengar, mencium bau, meraba, hingga muncul keputusan untuk membeli dan menggunakan produk

Sebuah kemasan haruslah dibuat berbeda dengan produk pesaingnya. Selain rasa, yang membedakan satu produk dengan produk lainnya yaitu nama mereknya. Konsumen akan memilih brand yang disuka, dan kemasan adalah medium brand-nya. Tanpa brand yang kuat, suatu saat produk akan tergerus oleh produk pesaing yang lebih inovatif dan mampu melakukan branding diri dengan baik. Tidak ada satupun produk yang dapat diperjualbelikan tanpa kemasan.

\section{Identitas Visual}

Identitas visual merupakan unsur pembentuk

asosiasi yang unik terhadap suatu brand. Karenanya suatu brand yang kuat akan tetap bertahan dalam persaingan pasar yang ketat dan bagaimana suatu brand dipersepsikan juga mempengaruhi kesuksesannya Identitas visual sangat dibutuhkan bagi sebuah brand agar mudah dikenali dan diingat oleh masyarakat. Identitas visual dapat mempresentasikan dirinya kepada masyarakat agar dapat dikenal lebih luas. Dengan dirancangnya identitas visual yang berkarakter, diharapkan dapat membantu memperkenalkan dan mempromosikan brand terkait. (Wheeler dalam Haiqal, 2017:424)

\section{Daya Tarik dalam Kemasan}

Daya tarik visual mengacu pada penampilan kemasan yang mencakup unsur grafis seperti warna, bentuk, merek/logo, ilustrasi, huruf/tipografi, dan layout. Semua unsur grafis tersebut dikombinasikan untuk menicptakan suatu kesan untuk memberikan daya tarik visual secara optimal. Daya tarik visual sendiri berhubungan dengan faktor 
emosi dan psikologis. (Cenadi dalam Erlyana, 2018:19).

Kemasan juga mempunyai peranan penting dalam bidang promosi, dalam hal ini kemasan berfungsi sebagai silent sales person. (Cenadi dalam Erlyana, 2018:20).

\section{METODE PENELITIAN}

Metode yang digunakan yaitu metode kualitatif. Metode kualitatif bersifat fleksibel sesuai kondisi Lapangan. Tidak seperti metode kuantitatif, metode kualitatif tidak memiliki variabel tertentu dalam proses pencarian datanya. Metode kualitatif lebih mengutamakan hal-hal yang bersifat pemaparan, bukan angka. Misalnya pengumpulan data dengan teknik wawancara kepada narasumber atau In Depth Interview untuk mendapatkan persepsi dari orang yang diteliti (Sarwono dan Hary, 2007:95-101).

Sedangkan metode analisis data yang digunakan adalah metode SWOT. Analisis SWOT digunakan terutama pada penilaian dan menilai ulang suatu hal yang sudah pernah ada sebelumnya dengan tujuan meminimalisir resiko yang mungkin saja timbul. Langkah analisisnya diawali dengan memilih dan menginventarisasi segi kekuatan (strength), kelemahan (weakness), kesempatan (opportunity), serta ancaman (threat). Dengan itu, sisi positif atau kelebihan dapat dioptimalkan untuk mendukung langkah meminimalisir kekurangan yang dapat menghambat pelaksanaan keputusan perancangan yang diambil. (Sarwono dan Hary, 2007:18).

Selain itu juga analisis berdasar teori-teori hasil studi pustaka dari sumber buku terpercaya yang sekiranya berhubungan dengan identitas visual dan kemasan.

\section{HASIL PEMBAHASAN}

Dua kriteria utama dalam metode ilmiah yaitu harus berdasarkan fakta serta terbebas dari prasangka penulis (Nazir,
2013:36). Maka dari itu, penulis melakukan wawancara kepada narasumber untuk mengetahui pendapat mereka mengenai kemasan Keripik Pisang Aneka.

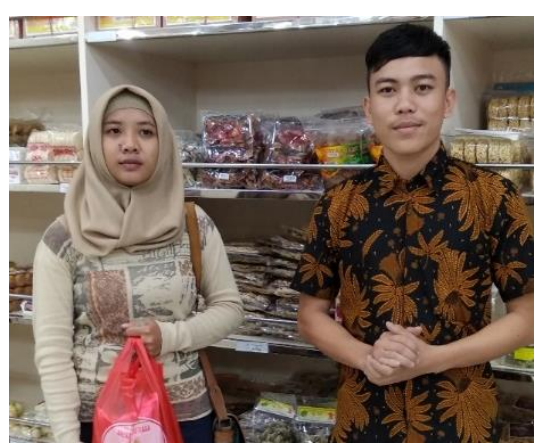

Gambar 2 Penulis Bersama Narasumber dari pihak Aneka

(Sumber: K. Setiawan, 2018)

Pada 14 April 2018, penulis melakukan wawancara kepada Agus sebagai narasumber dari pihak Yen Yen yang berlokasi di Jl. Ikan Kakap No. 86, Kecamatan Teluk Betung, Bandar Lampung. Menurut Agus, para pembeli biasanya ramai berdatangan di momen momen tertentu seperti tahun baru atau hari raya. Jumlah pengunjung di hari biasa berkisar antara tiga puluh hingga tujuh puluh transaksi. Sedangkan di momen tertentu seperti hari raya, akhir tahun, atau musim libur sekolah minimal dua ratus transaksi perhari. Produk utama yang mereka jual adalah Keripik Pisang Kepok Aneka dengan sebelas varian rasa. Agus mengakui bahwa kemasan keripik pisang mereka memang masih menggunakan desain yang belum diperbarui. Kemasan menggunakan kertas samson yang diikat pada tali kur berwarna merah sebagai pegangan dan penguncinya. Juga, kemasan Keripik Pisang Aneka memang sama sekali tidak mencerminkan bahwa produk tersebut merupakan produk khas Lampung.

Setelah melakukan analisis SWOT terhadap kemasan keripik pisang Aneka, terdapat beberapa hasil yang penulis dapatkan. 
Kekuatan (strength) dari kemasan keripik pisang Aneka yaitu berwarna coklat dengan material kertas samsons yang dapat menciptakan citra tradisional.

Kekurangannya (weakness) yaitu tidak terlihat identitas Lampung pada kemasan.

Kesempatan (opportunities) yang dapat dimanfaatkan yaitu kemasan keripik pisang Aneka dapat diberi sentuhan visual dari objek-objek yang identik dengan Lampung seperti flora, fauna, landmark, kerajinan khas, ataupun kesenian.

Ancaman (threat) yang mungkin diterima adalah munculnya produk keripik pisang dari merek lain dengan visual yang lebih menarik.

Analisis SWOT dapat membantu penulis untuk mengetahui kelemahan dan ancaman sebagai kelebihan dalam rancangan visual kemasan yang baru.

\section{Analisis SWOT tersebut} menghasilkan beberapa kelemahan yang dapat dijadikan kelebihan dalam perancangan kemasan baru. Metode yang digunakan penulis pada perancangan ini yaitu metode W-O (WeaknessOpportunities). Pada metode ini, kelemahan digunakan untuk mengisi kesempatan yang ada agar menjadi sebuah kelebihan.

Konsep pesan dari visualisasi kemasan ini adalah "Keripik pisang sebagai kuliner khas Lampung". Maka dari itu, konsep kreatifnya yaitu dengan menampilkan unsur-unsur visual Lampung seperti landmark, kesenian, kerajinan, flora, hingga fauna.

\section{Hasil rancangan}

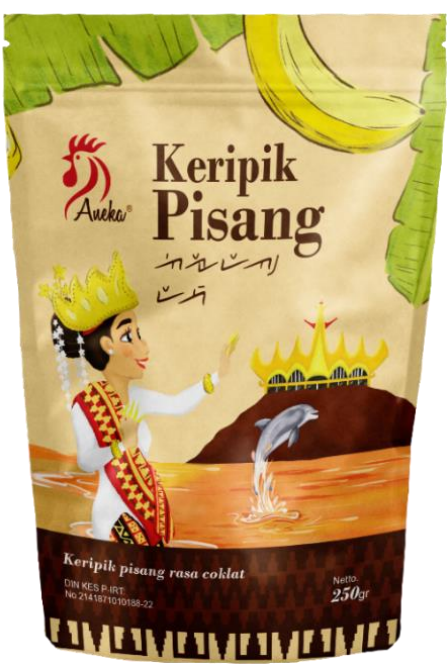

Gambar 3 Layout panel depan kemasan (Sumber: K. Setiawan, 2018)

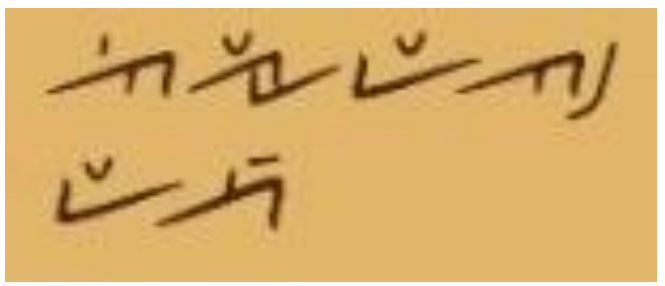

\section{Gambar 4 Penulisan kata Keripik Pisang dalam aksara Lampung (Sumber: K. Setiawan, 2018)}

Pada visualisasi panel depan kemasan (Gambar 3), terdapat beberapa unsur PDP (primary display panel) seperti logo, nama merek, nama produk, ilustrasi, berat bersih, dan nomor sertifikasi P-IRT. Pada kemasan ini, penulis memvisualisasikan identitas Lampung melalui ilustrasi dan aksara lampung untuk penulisan nama produk "keripik pisang". Ilustrasi pada panel depan kemasan yang menggambarkan identitas Lampung ada dua yaitu penari Lampung dan motif tapis Lampung pada bagian footer kemasan. 


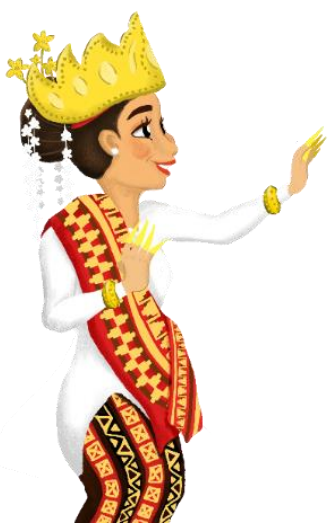

\section{Gambar 5 Ilustrasi Penari Sigeh Pengunten}

(Sumber: K. Setiawan, 2018)

Penari Lampung ini sedang membawakan tarian Sigeh Pengunten yang biasa dibawakan di acara-acara adat. Tari ini dibawakan sebagai sambutan atau ucapan selamat datang kepada tamu acara. Dengan kata lain, penari Sigeh Pengunten menjadi cirikhas utama pada kemasan Keripik Pisang Aneka ini menyambut para wisatawan yang sedang berkunjung ke Lampung dan mencari oleh-oleh untuk dibawa pulang. Penari menggunakan atribut tradisional Lampung mulai dari kain tapis yang dikenakan sebagai selendang, kain tapis untuk rok, giwang, kuku palsu, hingga siger (mahkota pengantin wanita Lampung).

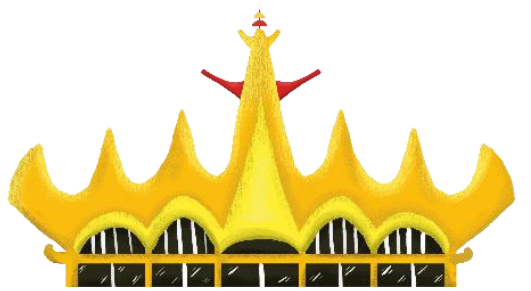

\section{Gambar 6 Ilustrasi Menara Siger sebagai landmark Lampung}

(Sumber: K. Setiawan, 2018)

Selain itu ada pula ilustrasi Menara Siger sebagai landmark Provinsi Lampung. Yang terakhir ada ilustrasi lumba-lumba yang diadaptasi dari Kiluan Dolphin. Kiluan merupakan destinasi wisata pantai yang ada di Lampung dan diminati wisatawan karena keberadaan lumba-lumba yang muncul (melompat ke udara) pada saat matahari terbit dan matahari terbenam. Maka dari itu, latar suasana yang digambarkan pada kemasan ini adalah ketika sunset (matahari terbenam).

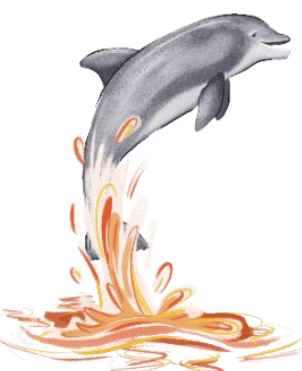

\section{Gambar 7 Ilustrasi Kiluan Dolphin}

(Sumber: K. Setiawan, 2018)

Kemudian pada visualisasi panel belakang kemasan (Gambar 8), terdapat beberapa unsur PDP seperti logo, nama merek, nama produk, deskripsi produk, tanggal kadaluwarsa, komposisi, kode batang, informasi layanan konsumen, dan ilustrasi.

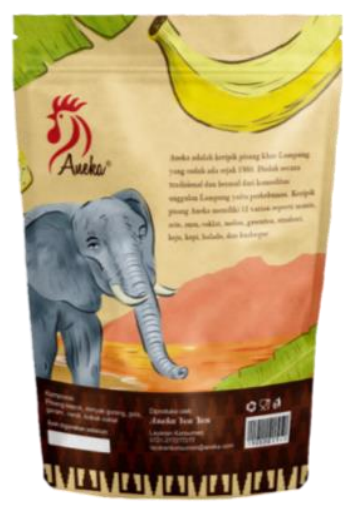

\section{Gambar 8 Layout Panel Belakang Kemasan \\ (Sumber: K. Setiawan, 2018)}

Visualisasi yang ditekankan pada rancangan ini adalah ilustrasi. Pada panel belakang, penulis menggunakan gajah sebagai cirikhas visual untuk menggambarkan fauna khas Lampung. Lampung memiliki Taman Nasional Way Kambas yang merupakan taman nasional perlindungan gajah. Hal inilah yang menyebabkan Lampung identik dengan 
Gajah. Pada ilustrasi latar terdapat visualisasi dari Gunung Rajabasa sebagai gunung tertinggi di Lampung. Gunung Rajabasa pada panel belakang digunakan sebagai landmark pendukung untuk menjelaskan keterangan tempat.

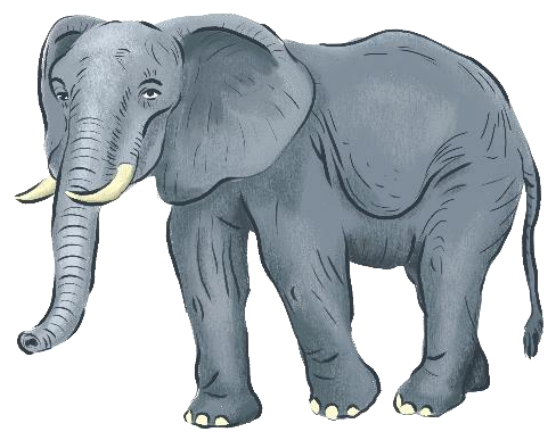

\section{Gambar 9 Ilustrasi gajah sebagai fauna khas Lampung \\ (Sumber: K. Setiawan, 2018)}

Kemudian pada footer kemasan terdapat motif tapis Lampung, sama seperti panel depan kemasan.

\section{SIMPULAN}

Kemasan merupakan alat yang berfungsi untuk membungkus suatu produk. Kemasan harus mampu menjual produk dengan sendirinya. Maka dari itu, kemasan haruslah mencerminkan citra produk melalui visualnya. Visual kemasan akan semakin baik apabila menampilkan cirikhas masingmasing produk. Sebab, tiap produk memiliki karakter yang berbeda. Sehingga, cirikhas tersebut akan menjadi pembeda antara satu produk dengan produk lainnya. Hal ini juga berlaku pada kemasan produk khas Lampung, ada beberapa unsur visual khas Lampung yang dapat ditampilkan agar mudah dikenal oleh khalayak sasaran bahwa produk tersebut merupakan produk/oleholeh khas Lampung. Setiap daerah memiliki perbedaan kekhasan yang dapat ditampilkan seperti landmark, flora, fauna, kesenian, hingga kerajinannya. Di Lampung, landmark yang paling terkenal adalah
Menara Siger yang terletak di Kalianda, dekat dengan Pelabuhan Bakauheni. Selain itu, ada fauna khas Lampung yaitu Gajah. Disamping fauna, ada flora Lampung yang dapat ditampilkan adalah pisang yang merupakan bahan utama produk keripik pisang sendiri. Untuk kerajinan, ada kain tapis Lampung yang digunakan pada penari Sigeh Pengunten yang mewakili kesenian Lampung. Dengan adanya visualisasi kekhasan daerah Lampung pada kemasan keripik pisang Aneka, masyarakat dapat mengetahui bahwa keripik pisang Aneka merupakan produk yang berasal dari Lampung.

\section{DAFTAR PUSTAKA}

Erlyana, Y., \& Nadya, N. 2018. Analisis Desain Kemasan Mi Instan Edisi Khusus Indomie Tempo Doloe. Titik Imaji, 1(1).

Haiqal, M. K., \& Hidayat, S. 2017. Penerapan Identitas Visual pada Media Promosi Website Wisata Kerajinan Rajapolah. Desain Komunikasi Visual, Manajemen Desain dan Periklanan (Demandia), 182-199.

Julianti, Sri. 2014. Art of Packaging Design: Mengenal Metode, Teknik, dan Strategi Pengemasan Produk untuk Branding Dengan Hasil Maksimal. Jakarta: PT Gramedia Pustaka Utama.

Nazir, Moh. 2013. Metode Penelitian. Bogor: Ghalia Indonesia.

Sarwono, Jonathan dan Hary. 2007. Metode Riset untuk Desain Komunikasi Visual. Yogyakarta: Penerbit Andi.

\section{Sumber Lainnya}

Andi Nur Aminah. 2017. Sri Mulyani Sebut Tol Trans Sumatera Dongkrak Perekonomian. www.republika.co.id 
/berita/ekonomi/makro/17/12/27/p1

ma4i384-sri-mulyani-sebut-tol-trans -sumatera-dongkrak-perekonomian (diakses 21 Maret 2018).

Bagus Prihantoro Nugroho. 2017. Jokowi Ingin Tingginya Ekonomi Lampung Berefek ke Orang Miskin. https://finance.detik.com/beritaekonomi-bisnis/d-3439142/jokowiingin-tingginya-ekonomi-lampungberefek-ke-orang-miskin (diakses 19 Mei 2018). 